FGV EBAPE

ESCOLA BRASILEIRA

DE ADMINISTRAÇÄO

PÚBLICA EDE

EMPRESAS
Programa de Pesquisa em Gestão da Aprendizagem Tecnológica e Inovação Industrial no Brasil, da EBAPE/FGV

Technological Learning and Industrial Innovation

Working Paper Series

www.ebape.fgv.br/tlit-wps

\title{
Inovação e Tecnologia no Brasil: Desafios e Insumos para o Desenvolvimento de Políticas Públicas
}

\author{
Carlos Ivan Simonsen Leal \\ Professor licenciado da EPGE Escola Brasileira de Economia \\ e Finanças da Fundação Getulio Vargas (FGV/EPGE) \\ Paulo N. Figueiredo \\ Professor titular da EBAPE Escola Brasileira de Administração Pública e \\ de Empresas da Fundação Getulio Vargas (FGV/EBAPE)
}




\title{
Inovação e Tecnologia no Brasil: Desafios e Insumos para o Desenvolvimento de Políticas Públicas*
}

\author{
Carlos Ivan Simonsen Leal \\ Professor licenciado da EPGE Escola Brasileira de Economia e Finanças da \\ Fundação Getulio Vargas (FGV/EPGE) \\ Paulo N. Figueiredo \\ Professor titular da EBAPE Escola Brasileira de Administração Pública \\ e de Empresas da Fundação Getulio Vargas (FGV/EBAPE)
}

\footnotetext{
* Trata-se de trabalho em processo de aprimoramento no âmbito da Fundação Getulio Vargas. Parte do conteúdo deste texto foi apresentada no IV Colóquio de Pesquisa Aplicada da Fundação Getulio Vargas (São Paulo, 21 e 22 Agosto 2018), em seminário na Financiadora de Inovação e Pesquisa (Finep, Rio de Janeiro, 29 Agosto 2018) e em evento sobre inovação e competitividade promovido pela Federação das Indústrias do Estado do Rio de Janeiro (Firjan) em conjunto com a Associação Brasileira das Empresas de Serviços de Petróleo (Rio de Janeiro, 24 Setembro 2018). O conteúdo deste documento reflete as ideias e perspectivas dos autores e não necessariamente as da Fundação Getulio Vargas.
} 


\section{Resumo Executivo}

Este documento apresenta uma breve reflexão sobre a natureza do investimento em pesquisa e desenvolvimento (P\&D) no Brasil. Comenta certos desafios relacionados a este tema na economia brasileira e oferece alguns insumos para o desenvolvimento de políticas públicas. O investimento do Brasil em P\&D tem aumentado continuamente ao longo dos últimos 15 anos comparativamente a outros países. Porém, os resultados deste esforço têm sido limitados em termos de inovação e produtividade. Por isso, este documento recomenda o aumento da eficácia dos dispêndios em P\&D no Brasil. 


\section{Sumário}

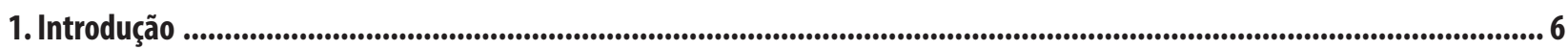

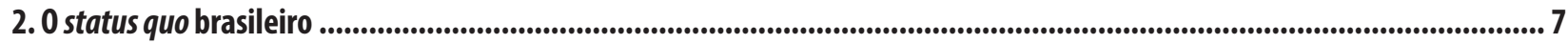

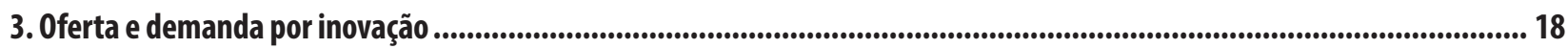

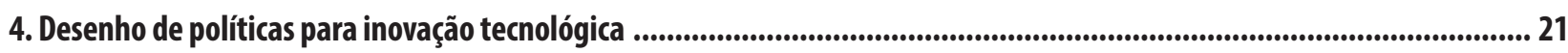

5. Inovação tecnológica: a necessidade de uma base organizacional.................................................................................. 26

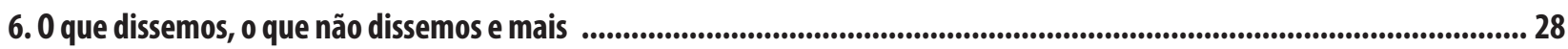

7. Alguns projetos potenciais de pesquisa sugeridos por este trabalho

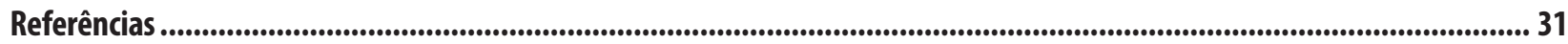




\section{Lista de Figuras}

Figura 1. Dispêndios nacionais em pesquisa e desenvolvimento (P\&D) em relação ao produto interno bruto (PIB) de países selecionados, 2000-2015.

Figura 2. Distribuição percentual dos dispêndios nacionais em $P \& D$, segundo fonte de financiamento, países selecionados, 2000-2015

Figura 3. Brasil vs. Coreia do Sul: Distribuição dos dispêndios governamentais em P\&D, por objetivos socioeconômicos, 2000-2015

Figura 3.1. Brasil e Coreia do Sul em posições inversas............................................................................................... 14

Figura 4. Mix entre taxa média de crescimento da produtividade e percentual de dispêndio governamental em tecnologia (2000-2016), por países (sem China)

Figura 5. Mix entre taxa média de crescimento da produtividade e taxa de investimento governamental em defesa por (2000-2016)

Figura 6. Relação entre ofertas e demandas por inovação ............................................................................ 18

Figura 7. Relação entre ofertas e demandas por inovação: uma perspectiva mais elaborada .................... 20

Figura 8. Exemplos de interações entre dimensões oferta e demanda da política de inovação ................ 24

Figura 9. Ilustração da 'escada de desenvolvimento tecnológico' em economias emergentes................... 27

\section{Lista de Quadros}

Quadro 1. Alguns exemplos de instrumentos de oferta e demanda da política de inovação.

Quadro 2. Alguns exemplos de políticas de apoio à inovação no Brasil, com orientação à oferta e à demanda

Quadro 3. Temas potenciais para projetos de pesquisa aplicada relacionados à economia e gestão da inovação tecnológica no Brasil 


\section{Introdução}

O Brasil precisa acelerar o seu desenvolvimento tecnológico e aumentar a taxa de inovação para agregar valor à produção nacional. De fato, o país vem pagando um alto preço pelo seu atraso tecnológico. A qualidade da pauta de exportações se deteriora, retornando o país a ser, cada vez mais, um exportador de produtos com baixo valor agregado. O setor público não consegue atender satisfatoriamente ao que Ihe é demandado, carecendo, simultaneamente, de uma maior eficácia e de um custo menor. O setor de serviços é, genericamente, de baixo valor agregado, tendo baixa integração com o setor industrial. Estes são apenas alguns exemplos importantes que expressam as dificuldades nacionais.

Por outro lado, onde, por alguma razão, houve a introdução de inovações relevantes, temos histórias de grande sucesso. A pesquisa agrícola da Embrapa, o desenvolvimento da exploração de petróleo em águas profundas, a liderança tecnológica e comercial, em nível internacional, obtida pela indústria de florestas e de celulose, as trajetórias da Embraer e da Vale são narrativas que devem ser motivo de exame e inspiração. Nelas se deve aprender como o desenvolvimento e a difusão de tecnologias podem impactar positivamente a agregação de valor.

No longo prazo, a capacidade do Brasil de atender aos justos anseios dos seus cidadãos dependerá de como se conseguirá proceder à alavancagem do desenvolvimento tecnológico e da inovação e sua difusão. Isto dependerá de como se podem alavancar recursos, sejam eles públicos ou privados e como conseguir o seu afinamento com as demandas do mercado.

A questão do investimento, da alavancagem e do foco no desenvolvimento tecnológico é complexa, envolvendo a necessidade de se compreender melhor as condicionantes a que está sujeita. Ela evolui ao longo do tempo e a sua própria mutação é influenciada por este processo.

Se também é preciso investir mais em desenvolvimento tecnológico e inovação, deve-se buscar maior retorno deste investimento. As condições fiscais de curto e médio prazo do país e o formato de várias das estruturas que deveriam levar a cabo a implementação destes investimentos são um impeditivo ao seu sucesso. Existiria, atualmente, uma conjuntura onde, racionalmente, a esperança nacional de obter um real desenvolvimento tecnológico próprio deveria ser reduzida a um mínimo.

Nesta curta nota, com base numa outra leitura da realidade, o nosso objetivo é contraditar esta conclusão. É fundamental entender o multifacetamento do desafio e não aceitar a derrota antes de ter lutado a batalha. É preciso aprofundar o entendimento do problema para ganhar graus de liberdade. 


\section{0 status quo brasileiro}

O aumento do ritmo de inovação tecnológica é uma das principais condições para o Brasil acelerar o seu crescimento econômico. O processo que permitiria que isto acontecesse demanda foco e investimentos. Todavia, fatores de conjuntura e de estrutura reduzem os recursos disponíveis para tal e, ao mesmo tempo, limitam a sua efetividade. Dois problemas são identificados:

(1) O investimento governamental precisa aumentar a sua eficácia.

(2) O investimento privado é pequeno, estando muito circunscrito às grandes empresas, sobretudo multinacionais.

De fato, 0 apoio governamental para novos investimentos em pesquisa e desenvolvimento (P\&D) tende a ser cada vez mais limitado e mesmo a manutenção dos atuais parece ser difícil. Esta dificuldade está associada, entre outros fatores, à demanda por recursos de outros setores, bem como impedimentos legais. Não obstante, ao longo dos últimos 15 anos, este investimento cresceu e alcançou patamares compatíveis com os do resto do mundo, mas os seus efeitos foram comparativamente menores.

O problema não é de simples compreensão. O Brasil tende a seguir o modelo europeu de investimento: mais em ciência básica do que em desenvolvimento tecnológico. Ele investe proporcionalmente pouco no desenvolvimento de tecnologia militar e o investimento privado não completa de forma adequada o investimento público. Em relação à tecnologia militar, vale mencionar que a indústria de defesa gera benefícios relevantes ao desenvolvimento tecnológico e econômico de países, como comentaremos mais adiante.

O investimento privado baixo é consequência do baixo grau de alavancagem criado como reflexo das finanças públicas e do excessivo grau de oligopolização da economia brasileira. A natureza do processo orçamentário brasileiro impede a criação de um efetivo benchmark para que a poupança privada se desloque na forma adequada para o investimento privado. Isto limita o financiamento de atividades com maior risco. Especialmente afetadas são as atividades de desenvolvimento tecnológico e inovação. Mesmo no caso de inovações locais, isto é, da simples adoção com adaptação de uma novidade que agregue valor, a qual já exista em outra parte do mundo, nota-se uma forte reticência.

Por outro lado, o fenômeno da excessiva oligopolização causado em parte pela estrutura tributária excessivamente dependente de impostos indiretos, desincentiva os investimentos em inovação. No curto e médio prazo, estas condições dificilmente serão mudadas. O país só poderá ter uma chance de aumentar o seu ritmo de inovação se entender melhor que processos deve mudar e como deve fazê-lo na questão dos dispêndios e incentivos governamentais. 
Sem a melhoria da eficácia dos dispêndios e incentivos em P\&D, o Brasil continuará gerando resultados pouco significativos em termos de inovação e produtividade e, consequentemente, lento crescimento econômico. As figuras a seguir elucidam o entrelaçamento de quatro dimensões a serem consideradas para possíveis soluções para este problema: o do nível de investimento total em P\&D como percentual do PIB, o da participação privada neste investimento, o do baixo foco no desenvolvimento tecnológico e o da composição civil versus militar deste investimento.

A Figura 1 mostra que o investimento do Brasil em P\&D como percentual do PIB tem aumentado continuamente de 2000 a 2015 comparativamente a outros países. A taxa de investimento do Brasil em P\&D é similar à de economias de renda alta, tais como Espanha $(1,2 \%)$ e Itália $(1,3 \%)$ e não tão distante da observada no Canadá (1,6\%).

No período 2015-2017, o Brasil se posicionou entre as 10 economias com maiores investimentos em P\&D, em termos absolutos. ${ }^{1} \mathbf{O}$ fato é que, ao contrário do que se pensa, o esforço do Brasil em termos de investimento em P\&D está longe de poder ser considerado insuficiente, levando-se em conta seu grau de desenvolvimento.

Figura 1. Dispêndios nacionais em pesquisa e desenvolvimento (P\&D) em relação ao produto interno bruto (PIB) de países selecionados, 2000-2015

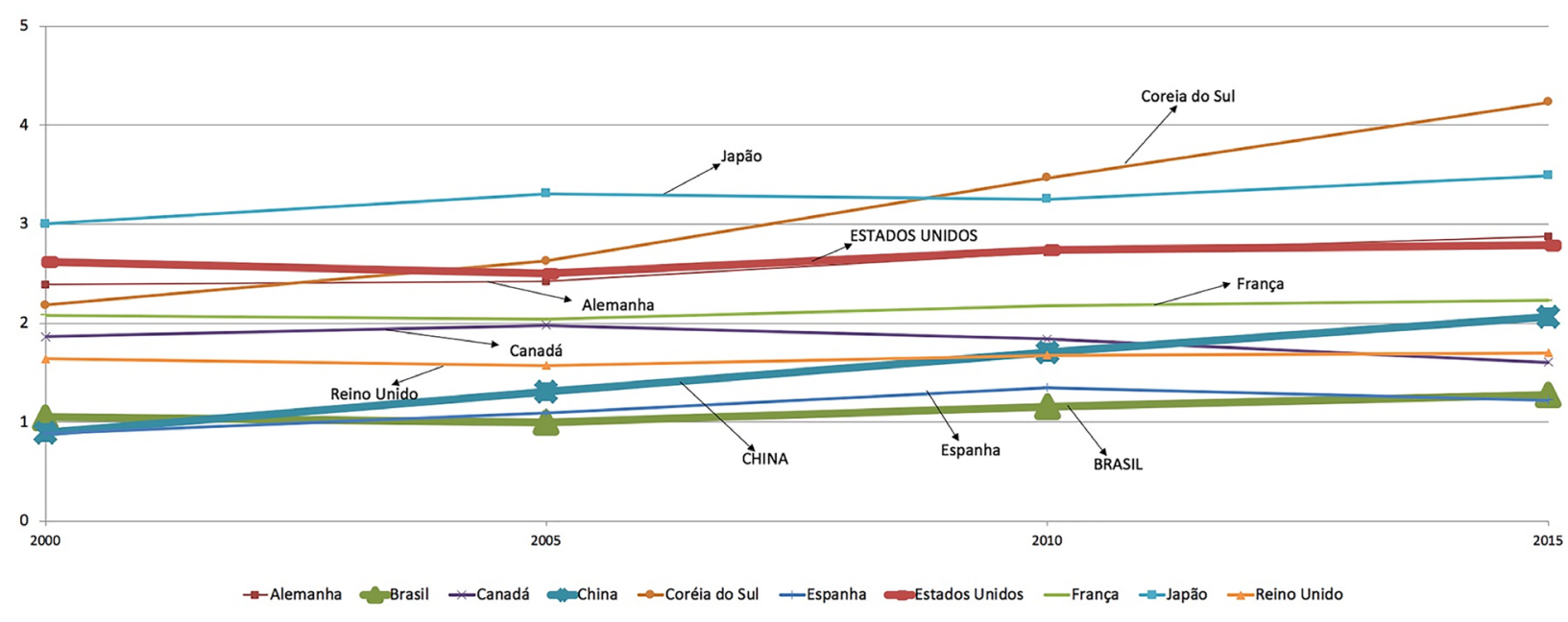

Fonte: MCTIC/OCDE

Todavia, a despeito da intensidade crescente dos seus investimentos em P\&D, o Brasil, como já foi dito, apresenta resultados pouco significativos em termos de inovação e aumento de produtividade, o que pode ser verificado pelos seguintes fatos:

(1) No Global Innovation Index, o Brasil caiu da 47a posição, em 2011, para a $69^{a}$ posição em 2016. ${ }^{2}$

\footnotetext{
${ }^{1}$ R\&D Magazine - www.rdmag.com

${ }^{2}$ Trata-se de publicação da Universidade de Cornell, em associação com o INSEAD e a Organização Mundial da Propriedade Intelectual (OMPI) - www.globalinnovationindex.org). O GIl baseia-se em 79 indicadores para calcular quatro medidas de inovação. A taxa de eficácia de inovação mede o quanto de resultado (inovação) um país obtém relativamente aos seus insumos, tais como investimentos em P\&D. Assim como índices agregados correlatos, este possui algumas limitações de natureza substantiva e metodológica. No entanto, é útil para nos proporcionar uma base inicial de aferição do desempenho inovador do Brasil.
} 
(2) No Relatório Global de Competitividade (2017-2018), do World Economic Forum, o Brasil ocupa a $80^{\mathrm{a}}$ posição.

(3) Na Pesquisa de Inovação do IBGE (Pintec, 2012-2014), as atividades inovadoras nas empresas amostradas são preponderantemente novas para elas $(15,5 \%$ em tecnologia de produto e $32,5 \%$ em tecnologia de processo). ${ }^{3}$

(4) Em relação ao aumento da produtividade, o Brasil ocupa uma das piores posições entre países com grau similar de desenvolvimento, segundo a Penn World Table ${ }^{4}$ e a Confederação Nacional da Indústria - CNI (2018).

(5) Em termos de valor agregado da indústria (VA/PIB), o resultado do Brasil em 2015 foi de 2,3\% (decrescente), contra 23,8\% da China (crescente) e 8,9\% (Japão), 6,4\% (Alemanha), e 3,1\% (Coreia do Sul, crescente), segundo a United Nations Industrial Development Organization (UNIDO).

Dada a taxa de investimento agregado do Brasil em P\&D, deveria ter havido benefícios muito mais significativos para a economia. Por que isto não aconteceu? Para responder a essa pergunta é preciso considerar a necessidade de maior presença do setor privado nos investimentos em P\&D.

Na Figura 2, o Brasil é o país que tem tido a maior participação estatal no esforço nacional em $P \& D$. Esta costumava ser a situação de algumas economias emergentes, entre elas a China e a Coreia do Sul e outras do Sudeste asiático, nas décadas de 1970 e 1980. Porém, esses países reverteram essa proporção de participação governamental nos dispêndios em P\&D nas décadas seguintes. Atualmente, esses países alinham-se à situação de economias avançadas. Uma característica comum aos países de renda alta, incluindo a Coreia do Sul, é que as empresas participam muito mais do que os governos no esforço nacional de P\&D.

A situação do Brasil, no entanto, permanece inalterada desde 2000. Esse quadro do Brasil é similar ao da média dos demais países latino-americanos. Enfim, o quadro brasileiro está na contramão da maioria das economias avançadas e, especialmente, do de países asiáticos, como Coreia do Sul e China. Nestes, o investimento empresarial em P\&D foi crescente no período 20002015 e superior ao investimento governamental. $\mathrm{E}$ isto acontece porque esses países foram paulatinamente criando condições de maior credibilidade para a base de financiamento aos investimentos de risco.

No entanto, no contexto brasileiro, é importante mencionar que a distribuição percentual dos dispêndios em P\&D no estado de São Paulo difere substancialmente daquela prevalente no Brasil. Cerca de $60 \%$ dos dispêndios em P\&D são realizados por empresas. Em outras palavras, a natureza dos dispêndios em P\&D no estado de São Paulo alinha-se à de economias avançadas, assim como à de países asiáticos, como Coreia do Sul e China. ${ }^{5}$

\footnotetext{
${ }^{3}$ A PINTEC é realizada a cada três anos, cobrindo os setores da indústria, serviços, eletricidade e gás. Na última edição da pesquisa, a amostra foi composta por aproximadamente 130.000 empresas.

${ }^{4}$ Ver Feenstra et al. (2015) e Confederação Nacional da Indústria (CNI, 2018).

${ }^{5}$ Ver www.fapesp.br [Indicadores de CT\&l em São Paulo, vários anos].
} 
Figura 2. Distribuição percentual dos dispêndios nacionais em $P \& D$, segundo fonte de financiamento, países selecionados, 2000-2015

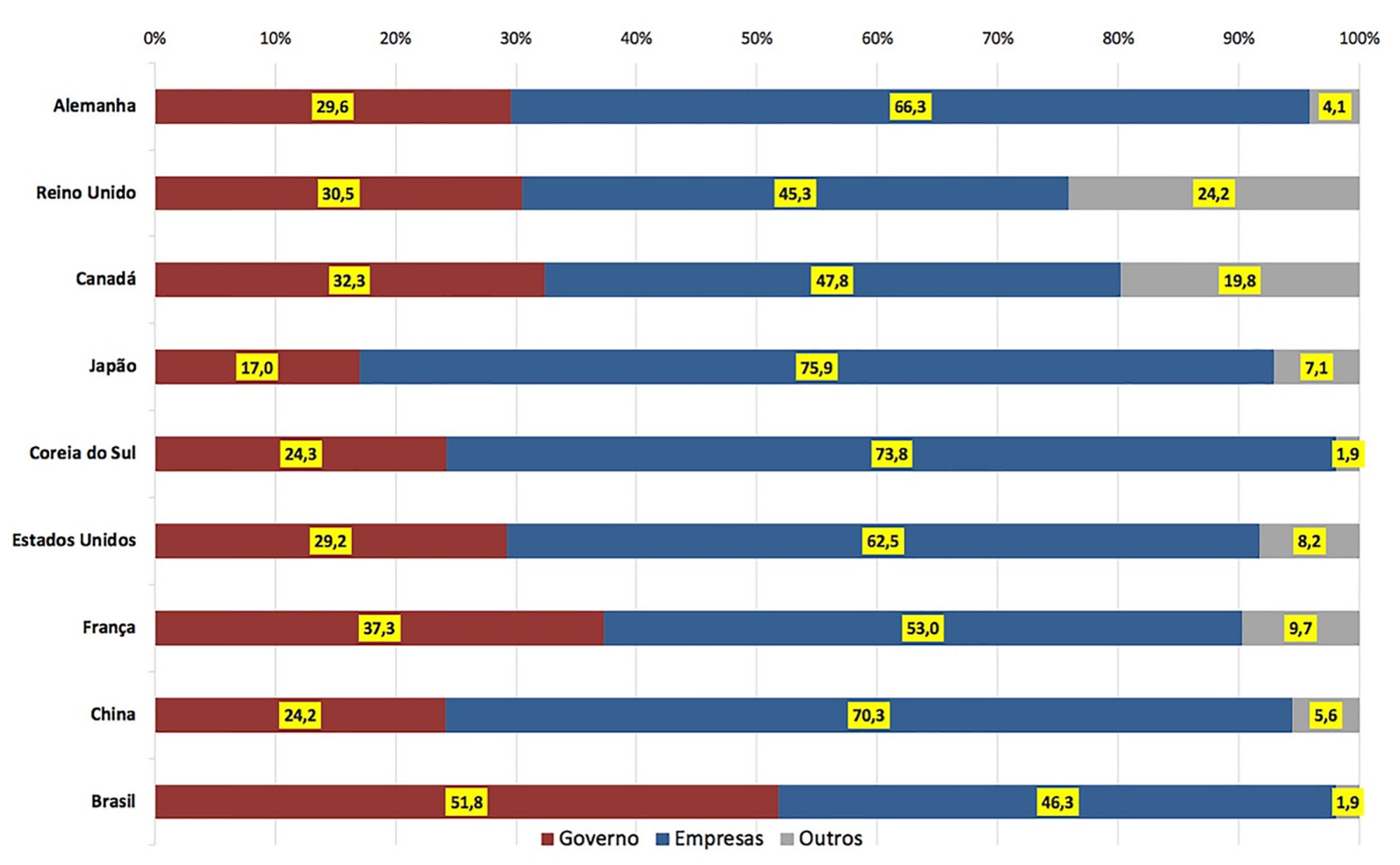

Fonte: MCTIC (Brasil) e www.stats.oecd.org.

Nota: 'Outros' inclui o ensino superior e instituições privadas sem fins lucrativos.

0 investimento privado em P\&D garante a aderência às demandas, forçando um maior foco em resultados. O seu objetivo é o desenvolvimento tecnológico e inovação. São as empresas que acumulam experiência e conhecimento específico e idiossincrático sobre aspectos técnicos de produtos, processos, e serviços e sobre a sua comercialização. Ademais, inovações em nível de empresas e sua rede de parceiros em vários setores da economia, são a base para produtividade e crescimento de países. Como amplamente demonstrado na literatura, empresas que inovam mais, e de maneira eficaz, obtêm melhor desempenho competitivo e crescimento de longo prazo. ${ }^{6}$

Considerando que o processo de inovação é implementado primordialmente pelas empresas, os ganhos de produtividade e o crescimento econômico de países dependem, em última análise, de empresas inovadoras.

Por outro lado, as inovações que as empresas implementam, individualmente ou em conjunto com seus parceiros, derivam de atividades criativas variadas tais como imitações, tentativa-e-erro e experimentações para soluções de problemas em produtos e processos, vários tipos de design e engenharia e vários níveis de P\&D.

Portanto, diversas inovações tecnológicas economicamente relevantes implementadas pelas empresas, nem sempre dependem de ciência. Pelo contrário, muitas vezes o oposto é a verdade. Várias inovações tecnológicas que surgiram na indústria criaram a base para uma agenda e avanços na ciência.

\footnotetext{
${ }^{6}$ Há uma ampla literatura sobre estes temas. Ver por exemplo, Fagerberg et al. (2005), Tidd \& Bessant (2013) e, para o contexto de economias emergentes, Figueiredo (2001), Bell \& Figueiredo (2012) e Lee (2013) entre outros.
} 
Conforme extensivamente demonstrado na literatura, a ideia da inovação tecnológica como uma mera aplicação do conhecimento científico é enganosa. Como afirma o clássico N. Rosenberg, tal perspectiva obscurece um ponto elementar que a tecnologia é, ela própria, um corpo de conhecimento específico sobre certos tipos de eventos e atividades.?

Também convém lembrarmos os clássicos estudos de $\mathrm{E}$. Mansfield que demonstraram que a grande maioria das inovações em produtos e processos em diferentes indústrias nos EUA foi implementada sem o benefício da pesquisa básica realizada em universidades. ${ }^{8}$

Análises subsequentes demonstraram que a maneira como empresas buscam o conhecimento científico da universidade para inovar varia consideravelmente entre setores industriais. ${ }^{9}$ Sabe-se que o êxito da interação entre empresa e universidade depende muito mais do ímpeto para inovar e da capacidade de absorção de conhecimento em nível da empresa. ${ }^{10}$ Por outro lado, tal êxito também depende da capacidade e interesse da universidade e seus pesquisadores de compreenderem a natureza dos problemas e demandas trazidos pelas empresas.

Porém, o papel primordial da empresa como ente implementador de inovações, não é amplamente compreendido, mesmo no âmbito de formuladores de políticas públicas. Especialmente nas economias em desenvolvimento, tende-se a atribuir, equivocadamente, às universidades e institutos públicos de pesquisa papel de principais atores (ou até mesmo 'exclusivos') no processo de inovação.

Ou seja, ainda prevalece a noção de que a inovação tecnológica, em nível da indústria e de empresas, decorre linearmente da aplicação do conhecimento científico desenvolvido em universidades e institutos de pesquisa. Como comentado anteriormente, esta perspectiva linear não reflete a realidade do processo de inovação tecnológica na indústria e na economia.

No entanto, no contexto do Brasil, como já observava Brito Cruz, tende a prevalecer a noção equivocada de que a inovação tecnológica ocorre mais na universidade do que na empresa. ${ }^{11}$ Esta perspectiva parece nutrir-se de mitos sobre o real papel das universidades em economias avançadas como os EUA, uma das economias mais intensivas em P\&D, como mostrado no Box 1.

\footnotetext{
${ }^{7}$ Ver Freeman (1974), Rosenberg (1982), Kline \& Rosenberg (1986), Fagerberg et al. (2005) e literatura relacionada.

${ }^{8}$ Ver Mansfield (1991) e estudos relacionados.

${ }^{9}$ Ver Salter \& Martin (2001).

${ }^{10}$ Ver Cohen \& Levinthal (1990), Meyer-Krahmer \& Schmoch (1998).

${ }^{11}$ Ver Brito-Cruz (2003).
} 
Box 1. Alguns mitos vs. evidências na relação indústria-universidade, EUA ${ }^{12}$

\begin{tabular}{|ll|}
\hline Mito: & Universidades nos EUA seriam geradoras de inventos que revolucionam a indústria. \\
& A formação de talentos e profissionais qualificados, a geração de resultados de \\
& pesquisa, instrumentos e técnicas são muito mais úteis para a indústria e para a \\
& economia. \\
Mito: & A pesquisa da universidade é que estimula a P\&D da indústria para obter vantagens \\
& destes inventos. \\
Evidência: & Grande parte dos projetos de P\&D da indústria reponde às necessidades atuais \\
& e potenciais de clientes de empresas; estas, buscam o P\&D da universidade para \\
& complementar suas atividades de P\&D e assim solucionar seus problemas técnicos para \\
& atender demandas e necessidades existentes e potenciais. \\
Mito: & Profissionais das universidades focariam somente em P\&D. \\
Evidência: & Há forte atuação de profissionais em atividades de engenharia e design, e não apenas \\
& em P\&D. \\
Mito: & Universidades teriam forte orientação teórica. \\
Evidência: & Parte considerável das universidades atua no atendimento de necessidades e soluções \\
& de problemas práticos da sociedade e da indústria.
\end{tabular}

Sabe-se que os investimentos em P\&D não têm o propósito exclusivo de gerar inovação tecnológica. Há objetivos importantes, como, por exemplo, a contribuição para uma base científica no país ou para o aprimoramento da regulação de atividades econômicas.

Porém, nosso foco aqui é em inovação e produtividade. Neste sentido, pode-se afirmar que o dispêndio nacional em P\&D tem sido ineficaz para gerar aplicação em termos de implementação de inovações na economia. Por isso, uma questão correlata à menor presença do setor privado nos investimentos em P\&D é a distribuição entre ciência básica e desenvolvimento tecnológico. Neste sentido, vale aqui uma breve comparação entre Brasil e Coreia do Sul.

No final da década de 1960, Brasil e Coreia do Sul apresentavam desempenho similar em termos de indicadores de desenvolvimento tecnológico e econômico. Quarenta anos depois a Coreia do Sul tornou-se uma economia de alta renda, com alto nível de produtividade e com liderança global tecnológica e comercial em várias indústrias.

O Brasil, por sua vez, continua estagnado na condição de renda média, com taxa de produtividade baixa, lento crescimento econômico e seus consequentes efeitos sociais. Por isso, esta comparação é relevante. A Figura 3 apresenta uma comparação aproximada entre Brasil (níveis federal e estadual) e Coreia do Sul, em termos da distribuição dos dispêndios governamentais em P\&D, por objetivos socioeconômicos, durante o período 2000-2015.

\footnotetext{
${ }^{12}$ Ver Mazzoleni \& Nelson (2007) e literatura relacionada.
} 
Figura 3. Brasil vs. Coreia do Sul: Distribuição dos dispêndios governamentais em P\&D, por objetivos socioeconômicos, 2000-2015

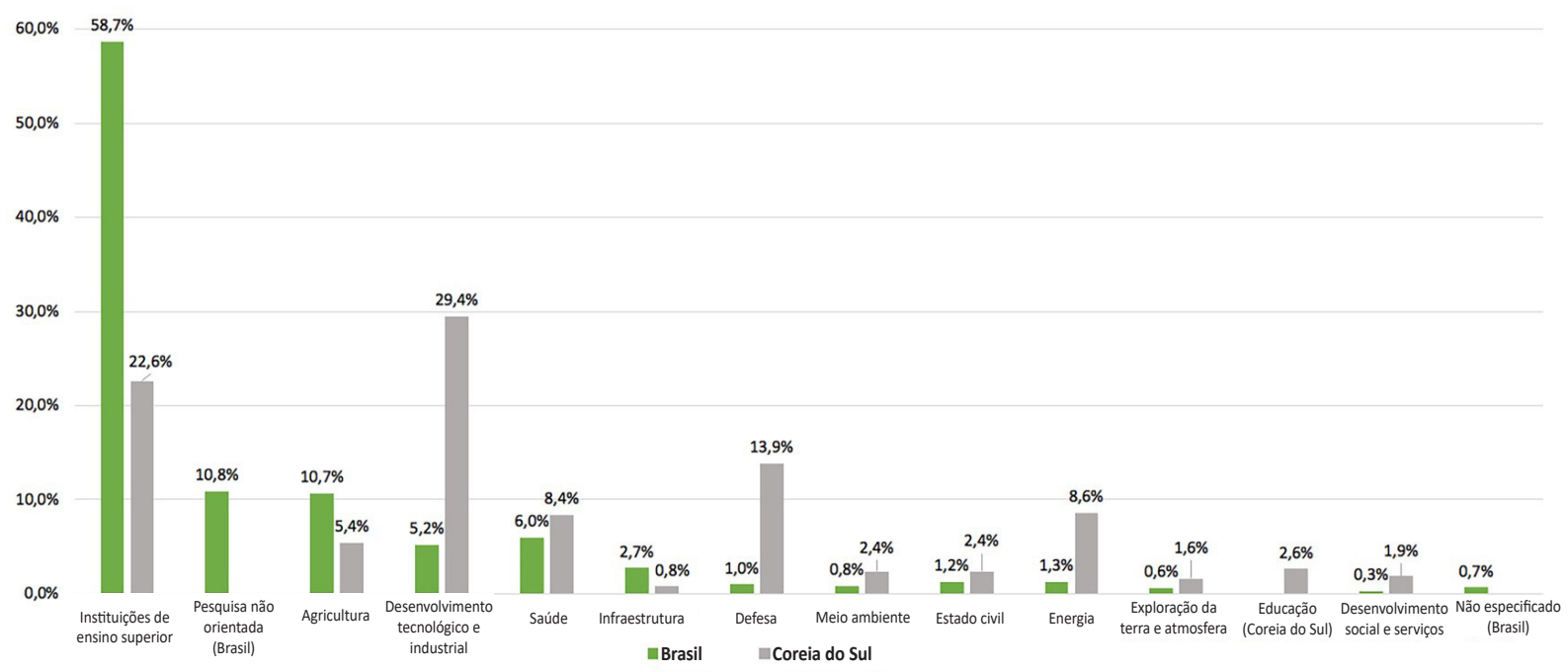

Fonte: Elaboração própria com base em dados do MCTIC (Brasil) e OECD (www.stats.oecd.org), capítulo GBARD.

Notas: (1) Brasil: média do período 2000-2014; Coreia do Sul = média do período 2000-2015. (2) Em relação ao objetivo socioeconômico 'Instituições de ensino superior', segundo o MCTIC: "Dos recursos anuais executados pelas instituições federais e estaduais com pós-graduação stricto sensu reconhecida pela CAPES, subtraem-se as despesas com juros e amortizações de dívidas, com o cumprimento de sentenças judiciais, com inativos e pensionistas e com a manutenção dos hospitais universitários, para estimar a parcela direcionada à pós-graduação multiplicando este resultado pelo quociente número de docentes da pós-graduação/número de docentes das IES do respectivo ano, à exceção dos anos de 2004 a 2006 nas instituições federais, quando foi empregado o quociente de 2003". Segundo o MCTIC, esta categoria inclui investimentos em prédios e demais instalações físicas e salários de professores e demais profissionais. (3) Segundo a contabilização da OCDE (vide MCTIC), nos países da OCDE a categoria 'Pesquisa não orientada' está incluída em 'Instituições de ensino superior'. (4) Percentuais calculados com base em valores a preços em USD constantes de 2011.

No Brasil as universidades (públicas, na grande maioria) têm absorvido a maior parte do investimento governamental em P\&D. ${ }^{13}$ Em nível estadual no Brasil, as universidades responderam pela grande maioria dos investimentos em P\&D, de 62,2\% (2000) para 71,4\% (2014), seguidos da 'Pesquisa não orientada' (média de 14\%, 2000-2014). Ou seja, grande parte dos dispêndios concentra-se no ensino superior e na produção científica, em detrimento do desenvolvimento tecnológico e implementação de inovações em outros componentes do sistema de inovação, especialmente as empresas.

$\mathrm{Na}$ Coreia do Sul, de 2000 a 2015, o dispêndio governamental em P\&D com as universidades evoluiu de 19,8\% para 20,8\%. Chamam a atenção os dispêndios em 'Desenvolvimento tecnológico e industrial': de 24,2\% (2000) para 29,2\% (2016).

Já a Figura 3.1, a seguir, apresenta as mesmas informações, porém de maneira ainda mais compactada. Os dispêndios governamentais de P\&D em tecnologia referem-se aos objetivos socioeconômicos da Figura 3, excluindo-se os dispêndios com 'Instituições de ensino superior' e 'Pesquisa não orientada.'

\footnotetext{
${ }^{13}$ Ver também UNESCO Science Report 2017 (capítulo Brasil) - www.en.unesco.org/unesco_science_report
} 
Figura 3.1. Brasil e Coreia do Sul em posições inversas

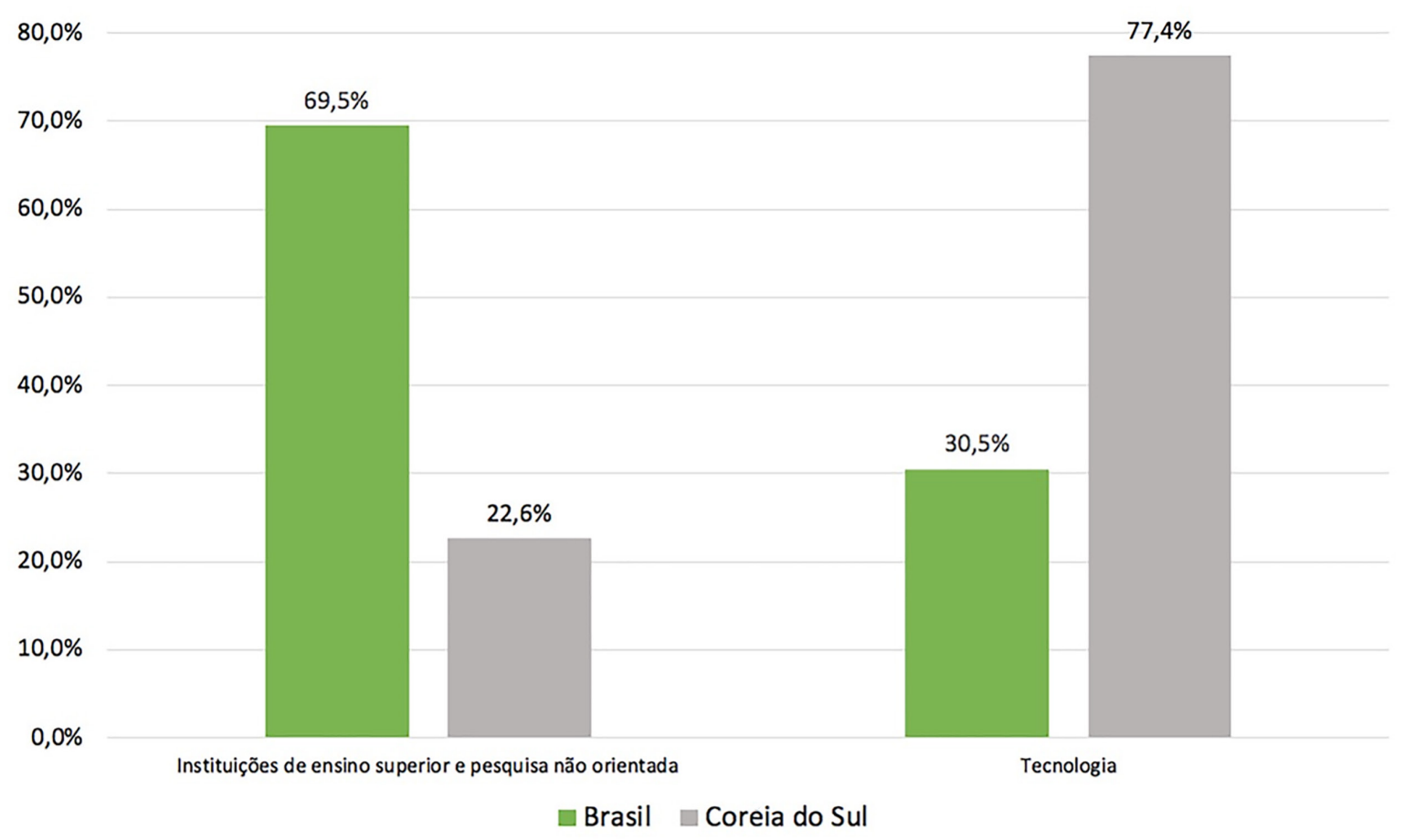

Fonte: Elaboração própria com base em dados do MCTIC (Brasil) e OECD (www.stats.oecd.org). Nota: Aplicam-se as mesmas observações da Figura 3.

Grande parte dos dispêndios da Coreia do Sul em P\&D tem sido direcionada ao desenvolvimento tecnológico e inovação. Estes dados corroboram os estudos existentes sobre a maneira pela qual Coreia do Sul conseguiu evoluir da condição de um país agrário, com baixas taxas de produtividade e de renda e baixo desenvolvimento industrial e tecnológico (décadas 1950 e 1960) para uma economia de alta renda e com liderança tecnológica e comercial em diversos tipos de indústrias: grande ênfase foi dada à crescente participação das empresas no investimento em P\&D do país.

Ao mesmo tempo, os investimentos governamentais em P\&D enfatizaram a pesquisa aplicada e o desenvolvimento experimental. Portanto, esses tipos de dispêndios em P\&D serviram de importante apoio à acumulação de capacidades tecnológicas para inovação em nível das empresas. ${ }^{14}$

Somente mais recentemente, após já ter alcançado alto nível de renda e alto nível de desenvolvimento industrial e tecnológico, a Coreia do Sul acelera seus esforços governamentais na direção da pesquisa básica, porém sem deixar de ter atenção à pesquisa aplicada e desenvolvimento experimental. ${ }^{15} \mathrm{~A}$ experiência da Coreia do Sul lança uma importante mensagem sobre a eficácia de dispêndios em P\&D para as demais economias emergentes, como a do Brasil.

As evidências da Coreia do Sul, assim como as de outros países que evoluíram de situação similar, contradizem a lógica predominante segundo a qual para se obter inovação industrial é necessário realizar esforços primordialmente em ciência.

\footnotetext{
${ }^{14}$ Para detalhes, ver Kim (1997) e Lee (2013).

${ }^{15}$ Ver OECD (www.stats.oecd.org).
} 
Especificamente, segundo esta lógica, a atenção da política pública deveria voltar-se para o fortalecimento da capacidade de pesquisa em universidades e institutos de pesquisa governamentais. Porém, a experiência coreana contraria este senso comum, o qual comentamos anteriormente: inovações com alto impacto econômico não necessariamente dependem de ciência.

Em suma, há no Brasil uma persistente predominância governamental no esforço nacional em P\&D. Dentro deste dispêndio governamental, a maior fatia é centralizada nas universidades e em pesquisa não orientada. Esta centralização exacerbada dos dispêndios nessas áreas contribui para uma baixa eficácia dos esforços brasileiros em P\&D. Não obstante, é importante considerar que o processo de inovação a base de P\&D é de alto risco. Por isso, não se pode ignorar o papel governamental neste processo, porém no sentido de um apoiador, financiador e estimulador eficaz, como é o caso da Coreia do Sul.

De maneira contrária, na Coreia do Sul os dispêndios públicos em P\&D são distribuídos de maneira decentralizada. Ao dispersar esses dispêndios em áreas associadas ao desenvolvimento tecnológico e industrial, a Coreia do Sul envolve um maior número de atores relacionados às atividades de produção, obtendo uma eficácia maior dos seus dispêndios governamentais em P\&D.

Convém aqui um breve comentário sobre esta centralização de atividades de P\&D em universidades e demais instituições públicas de pesquisa. ${ }^{16}$ Em primeiro lugar, trata-se de fenômeno prevalente em economias em desenvolvimento. Ela reflete uma noção específica do processo de inovação tecnológica e uma deficiência na base organizacional e de gestão dos esforços de P\&D. Mais especificamente, ela implica, usualmente, uma ênfase exacerbada no lado da oferta de P\&D. Considera as universidades e institutos públicos de pesquisa como lócus da inovação e geradores primordiais de insumos para a inovação tecnológica na indústria.

Em segundo lugar, ela expressa uma noção do sistema setorial de inovação que tende a ignorar os diversos atores envolvidos no processo de produção de bens e serviços e usuários. São eles que articulam a demanda por insumos para inovação tecnológica e jogam papel chave na sua implementação. Ocorre que esta base organizacional deficiente combinada com a precariedade de gestão em universidades e institutos públicos de pesquisa (embora haja exceções), somadas também às irregularidades e instabilidades de orçamento, não só limitam as pressões de demanda por P\&D, mas comprometem a eficácia do esforço nacional em P\&D.

Porém, países em desenvolvimento, particularmente, os asiáticos, corrigiram esta distorção ao longo das últimas décadas. Evidencias demonstram que a intensificação da descentralização ou dispersão das atividades de P\&D, para além das universidades e institutos públicos de pesquisa, gera diversos benefícios à economia, entre eles:

(1) Contribui para acelerar o processo de inovação tecnológica no tecido industrial (manufatura e não manufatura), que é o real lócus da inovação.

(2) As próprias atividades decentralizadas de P\&D atuam como fontes e canais para novas pressões de demanda por P\&D, criando um círculo virtuoso no sistema setorial de inovação.

\footnotetext{
${ }^{16}$ Ver Bell and Pavitt (1993), Bell and Figueiredo (2012), Figueiredo (2015).
} 
Portanto, considerar a oferta e a demanda das atividades e capacidades tecnológicas inovadoras contribui para acelerar o processo de inovação e aumento de produtividade. A Figura 4 mostra uma associação entre o percentual médio dos dispêndios governamentais de P\&D em tecnologia e a taxa média anual de crescimento da produtividade (2000-2016). ${ }^{17}$

A Coreia do Sul obteve uma taxa média de aumento de produtividade cinco vezes mais alta que a do Brasil de 2000 a 2016. É importante considerar que a produtividade nas economias avançadas (Europa, Japão e EUA) já se encontra em níveis elevados. Portanto, sua taxa de crescimento tende a ser mais lenta.

Figura 4. Mix entre taxa média de crescimento da produtividade e percentual de dispêndio governamental em tecnologia (2000-2016), por países (sem China)

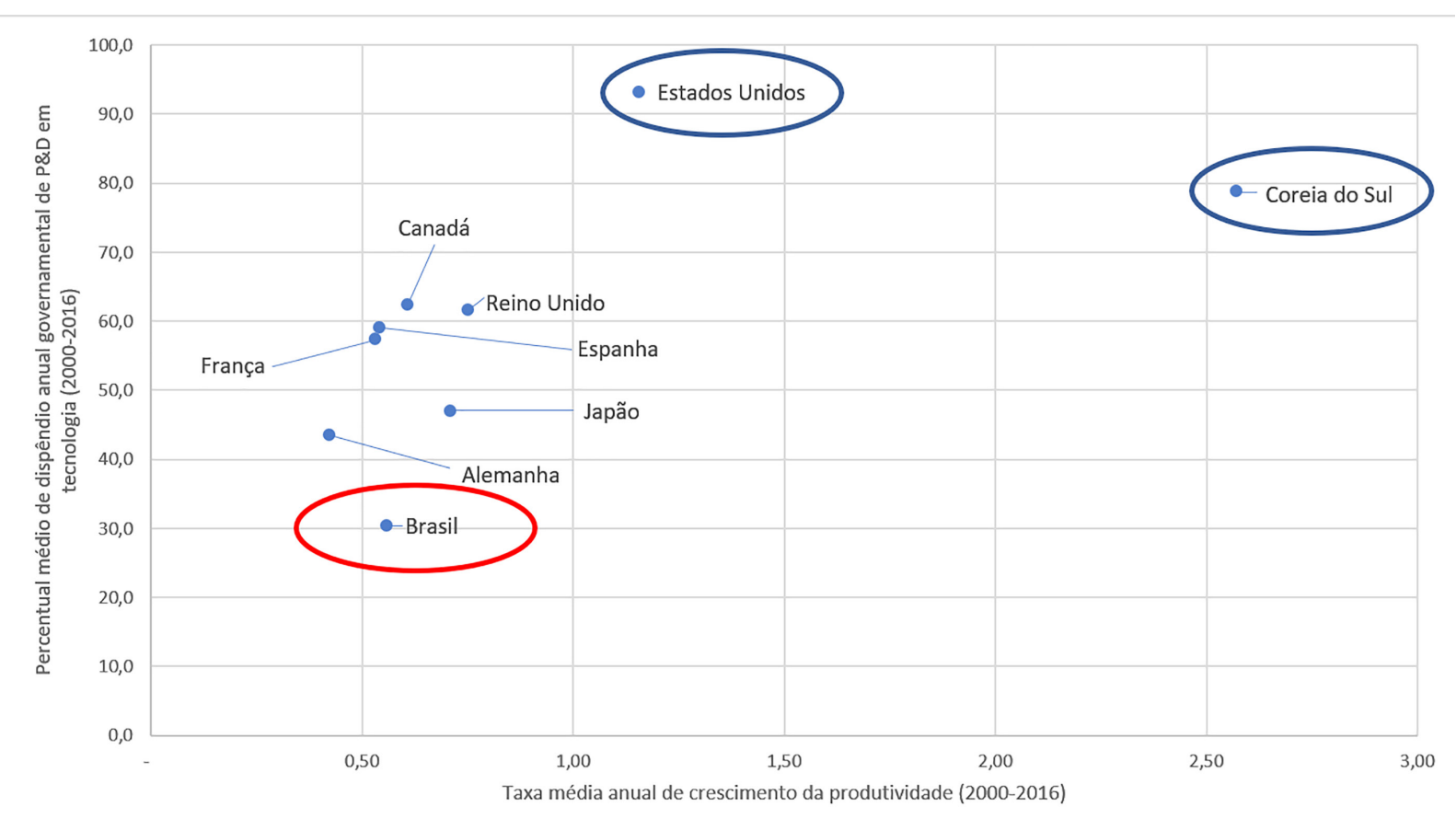

Fonte: OECD, MCTIC, World Bank.

A Figura 5, a seguir, mostra a combinação entre o percentual médio dos dispêndios governamentais de P\&D em defesa e a taxa média anual de crescimento da produtividade (2000-2016). Há farta documentação de evidências sobre os benefícios dos investimentos em P\&D na indústria de defesa para a economia, tais como demandas por $P \& D$, por inovações de outras indústrias, spill-overs tecnológicos, spin-offs inovadores, demanda por profissionais qualificados, desenvolvimento de tecnologias para usos múltiplos civis, etc.

\footnotetext{
${ }^{17}$ Os dispêndios governamentais de P\&D em tecnologia referem-se aos objetivos socioeconômicos da Figura 3, excluindo-se os dispêndios com 'Instituições de ensino superior' e 'Pesquisa não orientada'. A taxa de crescimento da produtividade (20002016) foi calculada a partir de dados do Banco Mundial https://data.worldbank.org/indicator/SL.GDP.PCAP.EM.KD?view=chart). O cálculo é feito a partir do PIB per capita por pessoa empregada, com preços constantes em dólares de 2011. Para facilitar a comparação entre países, os dados também são equivalentes em paridade de poder de compra. Esta proxy para produtividade do trabalho é utilizada internacionalmente em estudos comparativos.
} 
Figura 5. Mix entre taxa média de crescimento da produtividade e taxa de investimento governamental em defesa por (2000-2016)

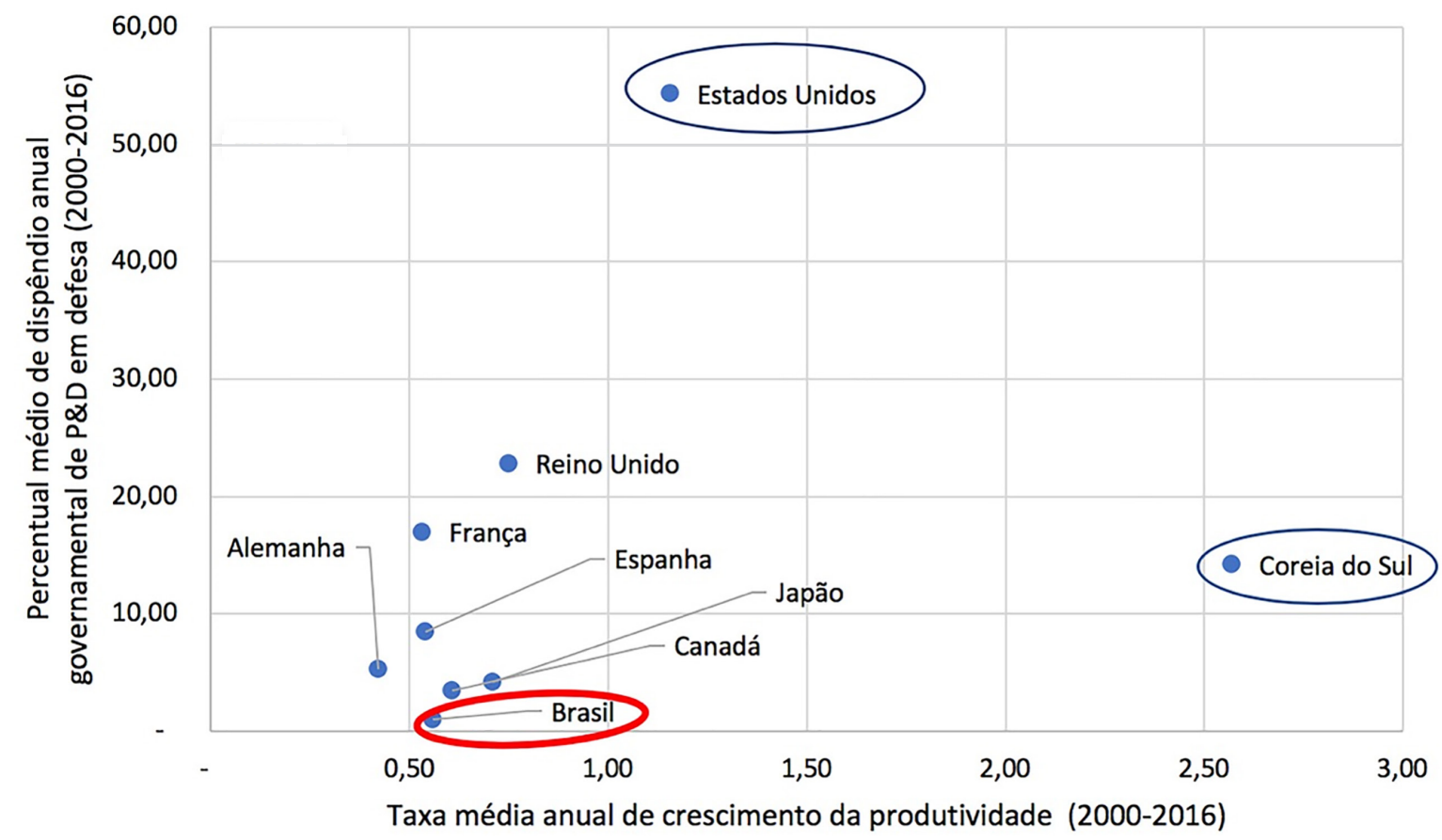

Fonte: OECD, MCTIC, World Bank

Qualquer solução para o problema brasileiro terá que levar em conta essas considerações. Faremos isso nas seções seguintes. Porém, consideremos primeiro o modelo de base para entender e poder sugerir insumos iniciais para desenhar uma estratégia de solução. 


\section{Oferta e demanda por inovação}

Há diferentes conceitos ligados à ideia de inovação, tais como os de inovação incremental e disruptiva, o de portfólio de inovações e gestão de risco versus retorno das inovações, o dos condicionantes ou limitantes da inovação, etc. Todos podem ser enquadrados e/ou analisados usando um desenho simples que relaciona a oferta de inovação com as suas demandas, como representado no diagrama da Figura 6 a seguir.

Figura 6. Relação entre ofertas e demandas por inovação

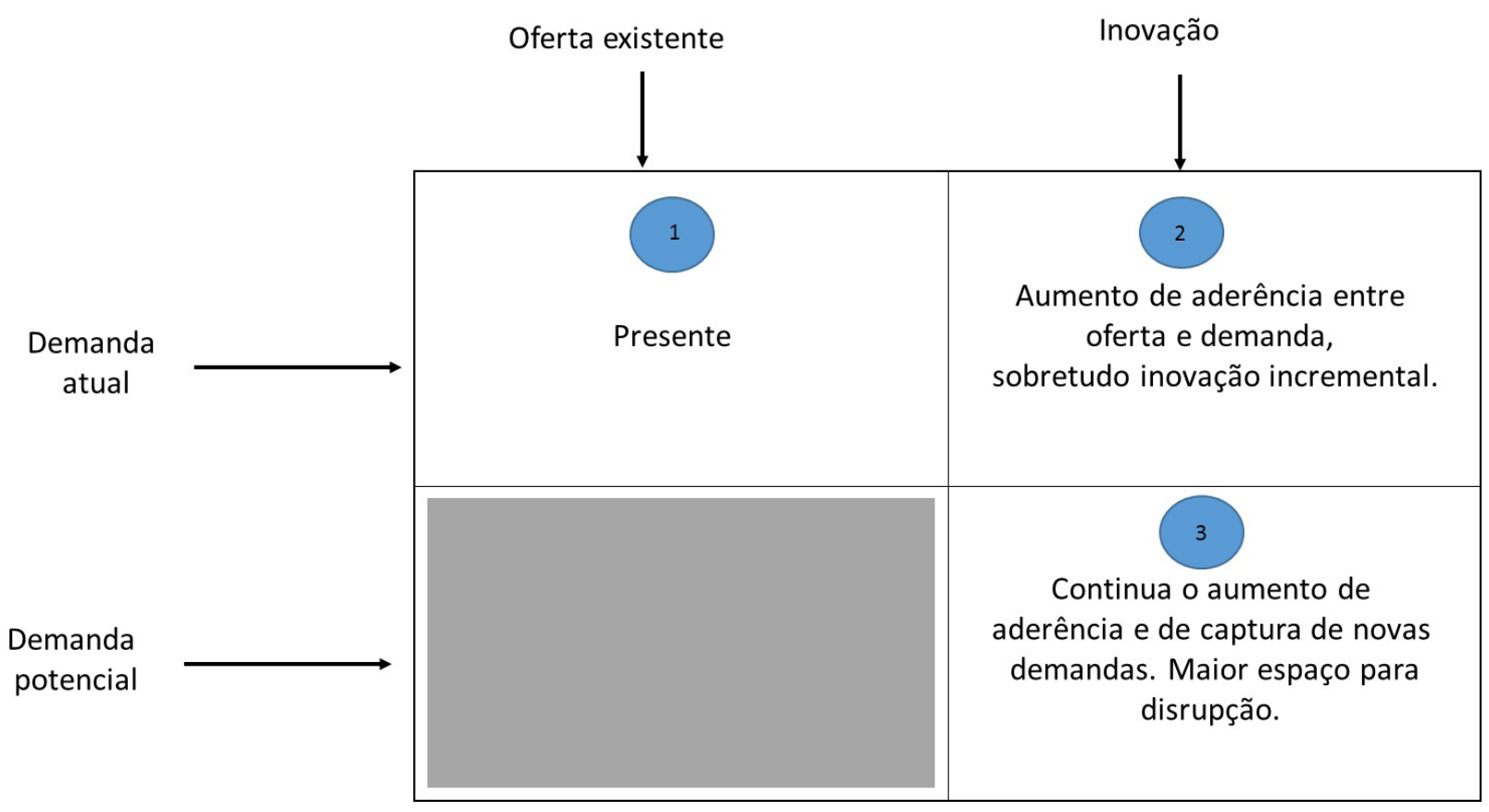

Em 1 temos o status quo: as ofertas existentes estão casadas com as demandas atuais e, geralmente, podem ser adaptadas para as flutuações pequenas destas.

Em 2 as inovações são, sobretudo, incrementais e, mais ainda, geralmente focam em ganho de eficiência, seja via melhoria de processos, seja por meio de pequenos aprimoramentos nos produtos. A baixa de custo, sobretudo na sua difusão, permite atender demandas ainda não atendidas.

Em 3 a mudança inclui menos as reduções de custo e mais a capacidade de alcançar novas demandas. A diferença entre a incrementalidade e a disruptividade está no tamanho do salto que se dá e na velocidade de sua consecução. O quadrante sombreado corresponde às demandas potencialmente existentes que hoje não podem ser atendidas.

O trajeto natural em uma economia é procurar ir adicionando, sucessivamente, o quadrante $\mathbf{2}$ ao $\mathbf{1}$ e, depois, o $\mathbf{3}$ ao $\mathbf{1}$ e ao $\mathbf{2}$. Ao longo do tempo, isto significa que se vai aumentando o uso e a 
difusão de inovações e agregação de valor na economia. É muito difícil, do ponto de vista da sustentabilidade econômica, operar diretamente o quadrante 3.

A razão é que processos de inovação disruptiva têm muitos riscos. Citemos alguns:

(1) Por definição, o volume de investimentos necessários para chegar a um resultado é mais volátil com um viés para cima.

(2) O retorno também é volátil com um viés, desta vez, geralmente, para baixo.

\section{O Brasil distribui seus investimentos em P\&D de maneira pouco eficaz e adota poucas, ou quase nenhuma, das medidas e procedimentos de segurança necessários à gestão do risco de portfólio de inovação. De um modo geral, pode-se dizer que o país ignora como fazer isto.}

Em primeiro lugar, a distribuição entre ciência básica e tecnologia, o coloca mais na busca de algo no quadrante $\mathbf{3}$ do que no quadrante $\mathbf{2}$.

Em segundo lugar, a própria distribuição do investimento governamental em P\&D no Brasil, como mostramos anteriormente, é concentrada em universidades e em pesquisa não orientada. Ou seja, o dispêndio público é primordialmente orientado ao fomento da ciência em si. Dentro desta esfera, é extremamente pulverizado em um sem números de linhas de pesquisa, devido a questões de tamanho mínimos de investimentos, limitando a sua eficacidade e também por estar sujeita às incertezas da execução orçamentária governamental.

Em terceiro lugar, a baixa proporção, quase nula, do investimento militar significa que um potente instrumento de subsídio focado, onde seguramente os resultados acontecem, não é explorado. $\mathrm{O}$ investimento militar, em conjunto com o resto, reduz a volatilidade do retorno deste investimento. Ao mesmo tempo, ele pode ser usado como uma fonte inteligente de subsídios para o desenvolvimento tecnológico. Historicamente, nos países desenvolvidos, o investimento militar reduz, em processos de inovação incremental, o custo total do investimento.

Aprofundando a análise acima, as demandas potenciais podem ser divididas entre as que percebemos hoje e as que ainda não conhecemos. Por outro lado, algo semelhante pode ser feito com as inovações. Isto nos daria um refinamento conforme mostrado no diagrama a seguir (Figura 7). Fica aqui ainda mais nítido o problema: qual a sequência correta de retângulos a ser ocupada? Não parece que o Brasil entendeu essa questão corretamente. 
Figura 7. Relação entre ofertas e demandas por inovação: uma perspectiva mais elaborada

\begin{tabular}{l|l|l|l|}
\hline $\begin{array}{l}\text { Ofertas } \\
\text { existentes }\end{array}$ & $\begin{array}{c}\text { Ofertas ainda não existentes, } \\
\text { mas incrementalmente }\end{array}$ \\
\hline $\begin{array}{l}\text { Demandas } \\
\text { existentes }\end{array}$ \\
$\begin{array}{l}\text { Demandas } \\
\text { potenciais } \\
\text { percebidas }\end{array}$ \\
$\begin{array}{l}\text { Demandas } \\
\text { potenciais } \\
\text { não } \\
\text { percebidas }\end{array}$
\end{tabular}




\section{Desenho de políticas para inovação tecnológica}

Conforme vislumbramos na seção anterior, estratégias nacionais de inovação são necessárias. Isto porque há uma crescente necessidade de países obterem ganhos de produtividade e competirem no mercado global a base de produtos com maior valor agregado e grau de novidade. Ao mesmo tempo, forças de mercado, por si sós, não garantem a implementação de inovações em nível das empresas. Consideremos os seguintes pontos:

(1) É importante frisar que inovação não significa somente novas ideias e inventividade. Esta noção sempre embasou as políticas científicas no passado. Pelo contrário, inovação envolve a agregação de valor a ideias e sua implementação prática. Seu objetivo é aumentar a produtividade e responder a problemas, necessidades e desafios existentes e potenciais na sociedade. É a sua orientação para solução de problemas que faz da inovação um fator relevante para gestores públicos enfrentarem questões técnicas, econômicas e sociais no país.

(2) Inovações derivam de um amplo espectro de atividades e capacidades tecnológicas que envolvem por exemplo, experimentações, imitações criativas, soluções de problemas a base de engenharia, design, desenvolvimento experimental até o mais avançado nível de P\&D em nível de empresas.

(3) Portanto, é um equívoco associar inovação à mera aplicação do conhecimento científico. No entanto, como comentado anteriormente, esta perspectiva linear sobre inovação - i.e., a de que pesquisa científica básica, realizada em universidades e em institutos públicos de pesquisa, levaria à inovação tecnológica - ainda é invocada para justificar o aumento de dispêndios governamentais em P\&D. Como dito, várias inovações relevantes não necessariamente dependem de ciência.

(4) De fato, o processo de inovação tem se tornado cada vez mais fragmentado e disperso. Empresas inovadoras colaboram com vários parceiros, tais como fornecedores, usuários, startups (com finalidades diversas), consultorias especializadas, competidores, universidades, institutos de pesquisa etc. Mas essa colaboração não significa 'transferir' para os parceiros a atividade de inovação. A empresa produtora continua retendo o papel fundamental de liderar e 'puxar' o processo de inovação.

(5) Políticas de inovação envolvem uma intervenção pública para apoiar a geração e a difusão de novos produtos, processos ou serviços, mas também novos modelos de negócio e arranjos organizacionais, novas formas de comercialização de distribuição de produtos, novos insumos para produção, entre outras atividades inovadoras. 
Por isso, nosso foco aqui recai sobre medidas para aumentar o investimento do setor privado em P\&D e a taxa de inovação da economia. A literatura e a experiência de países identificam instrumentos de política orientados para estimular a inovação direta e/ou indiretamente. Tais instrumentos podem ser classificados como sendo relacionados ao lado da oferta (os que influenciam a geração de inovação) ou ao lado da demanda (os que influenciam aqueles que requerem/desejam, compram ou aplicam inovações e os insumos para implementá-las).

As políticas centradas somente no lado da oferta, que, em grande parte, tendem a não considerar aplicações comerciais, têm sido insuficientes para a geração e implementação de inovações. Ao mesmo tempo, há um consenso sobre o papel fundamental desempenhado pelas empresas e sua rede de parceiros, no processo eficaz de inovação e aumento de produtividade. Durante as últimas décadas vários países desenvolvidos têm valorizado as políticas de inovação orientadas para a demanda em conexão com as de oferta.

Tais políticas específicas podem e devem ter no seu desenho o uso dos seguintes instrumentos do Quadro 1, a seguir. Estes são classificados de acordo com o seu maior foco na oferta ou na demanda. Os exemplos do Quadro 1 não são exaustivos, mas já permitem vislumbrar a complexidade da análise a ser feita. 
Quadro 1. Alguns exemplos de instrumentos de oferta e demanda da política de inovação

\begin{tabular}{|c|c|c|c|}
\hline $\begin{array}{l}\text { Exemplos de instrumentos de oferta e } \\
\text { demanda política de inovação }\end{array}$ & Oferta & Demanda & $\begin{array}{l}\text { Objetivos e impactos } \\
\text { esperados }\end{array}$ \\
\hline Incentivos fiscais a P\&D & $\checkmark$ & & \multirow{3}{*}{ Aumentar gastos em P\&D } \\
\hline Suporte direto a P\&D nas empresas & $\checkmark$ & & \\
\hline Acesso a financiamento e garantias de empréstimo & $\checkmark$ & & \\
\hline $\begin{array}{l}\text { Políticas para treinamento e qualificação de recursos humanos para } \\
\text { empresas }\end{array}$ & $\checkmark$ & & \multirow{2}{*}{$\begin{array}{c}\text { Aumentar nível de } \\
\text { qualificação de recursos } \\
\text { humanos (skills) }\end{array}$} \\
\hline Políticas de migração de recursos humanos e proteção ao emprego & $\checkmark$ & & \\
\hline Medidas de apoio à proteção de propriedade intelectual & $\checkmark$ & & \multirow{3}{*}{ Acesso a especialistas } \\
\hline $\begin{array}{l}\text { Política de apoio ao empreendedorismo (incluindo incubadoras e } \\
\text { mecanismos similares) }\end{array}$ & $\checkmark$ & & \\
\hline Serviços de apoio técnico e aconselhamento & $\checkmark$ & & \\
\hline Política de cluster & $\checkmark$ & & \multirow{3}{*}{$\begin{array}{l}\text { Desenvolvimento de } \\
\text { capacidades sistêmicas }\end{array}$} \\
\hline Política de apoio à colaboração para P\&D & $\checkmark$ & & \\
\hline Política de formação de redes de inovação & $\checkmark$ & & \\
\hline Estímulo a demandas por inovação & & $\checkmark$ & \multirow{13}{*}{$\begin{array}{l}\text { Aumento da demanda } \\
\text { do setor privado e de } \\
\text { consumidores por inovação }\end{array}$} \\
\hline Política de compras governamentais & & $\checkmark$ & \\
\hline Políticas de compras pré-comerciais & & $\checkmark$ & \\
\hline $\begin{array}{l}\text { Políticas de compras cooperativa e catalisadoras (governo em conexão } \\
\text { com empresas) }\end{array}$ & & $\checkmark$ & \\
\hline $\begin{array}{l}\text { Criação de guia e ferramentas orientadas à inovação para apoiar os } \\
\text { processos de compras governamentais com exemplos de boas práticas }\end{array}$ & & $\checkmark$ & \\
\hline $\begin{array}{l}\text { Medidas de redução de barreiras para participação de PMEs no } \\
\text { processo de compra governamental }\end{array}$ & & $\checkmark$ & \\
\hline $\begin{array}{l}\text { Processos competitivos para empreendedores inovadores nas } \\
\text { compras governamentais }\end{array}$ & & $\checkmark$ & \\
\hline Contratos de reembolso de custos & & $\checkmark$ & \\
\hline $\begin{array}{l}\text { Criação de incentivos para estimular demanda por novos produtos e } \\
\text { serviços }\end{array}$ & & $\checkmark$ & \\
\hline $\begin{array}{l}\text { Medidas para conscientizar e estimular consumidores para novos } \\
\text { produtos e serviços }\end{array}$ & & $\checkmark$ & \\
\hline Várias medidas de padronização & & $\checkmark$ & \\
\hline Várias formas de regulação & & $\checkmark$ & \\
\hline Prêmios indutores de inovação & & $\checkmark$ & \\
\hline $\begin{array}{l}\text { Medidas de estímulo ao desenvolvimento de capacidades } \\
\text { tecnológicas para inovação em empresas }\end{array}$ & $\checkmark$ & $\checkmark$ & \multirow{3}{*}{$\begin{array}{c}\text { Desenvolvimento de } \\
\text { capacidades para inovação em } \\
\text { empresas ao longo da cadeia } \\
\text { de valor }\end{array}$} \\
\hline Spill-overs gerados por inovações tecnológicas na indústria de defesa & $\checkmark$ & $\checkmark$ & \\
\hline $\begin{array}{l}\text { Organizações dedicadas ao alinhamento entre demanda e oferta de } \\
\text { universidades, institutos públicos de pesquisa e empresas }\end{array}$ & $\checkmark$ & $\checkmark$ & \\
\hline
\end{tabular}

Fonte: Adaptado de Edler (2013); European Commission (2015); Edler \& Fagerberg, 2017.

$=$ Interseção entre oferta e demanda.

A Figura 8, a seguir, apresenta alguns exemplos de interações entre as dimensões oferta e demanda de políticas públicas orientadas para a inovação. 
Figura 8. Exemplos de interações entre dimensões oferta e demanda da política de inovação

\section{Demandas}

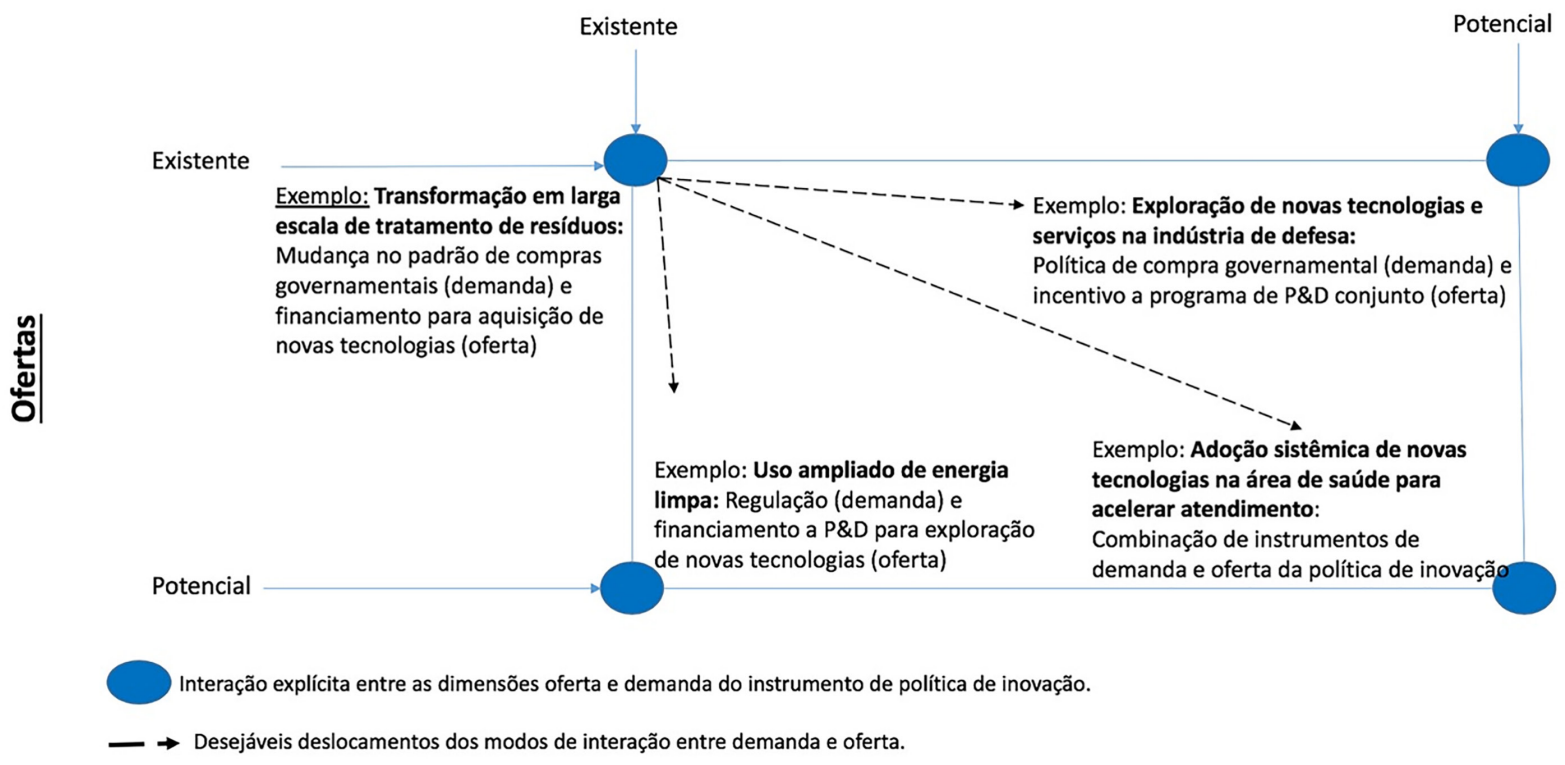

Ao longo dos últimos 20 anos o Brasil criou um conjunto de políticas de apoio à inovação. Estas políticas têm sido implementadas na forma de diversos programas e ações. É interessante observar que as políticas implementadas no Brasil ao longo dos últimos 20 anos têm enfatizado, em sua maioria, o lado da oferta, em detrimento do lado da demanda. O Quadro 2, a seguir, apresenta alguns exemplos dessas políticas. 
Quadro 2. Alguns exemplos de políticas de apoio à inovação no Brasil, com orientação à oferta e à demanda

\begin{tabular}{|c|c|c|c|}
\hline \multirow{3}{*}{ Orientação à oferta } & \multirow[t]{2}{*}{$\begin{array}{l}\text { Apoio financeiro } \\
\text { indireto }\end{array}$} & Incentivos fiscais & $\begin{array}{l}\text { - Criação dos fundos setoriais (final } \\
\text { da década de 1990) } \\
\text { - Incentivos fiscais da Lei de Informática } \\
\text { (Leis nº 8.248/1991 e 10.176/2001). } \\
\text { - Política Industrial, Tecnológica e de } \\
\text { Comércio Exterior (Pitce), 2004. } \\
\text { - Lei de Inovação (Lei no 10.973/2004) } \\
\text { - Lei do Bem (Lei no 11.196, de 2005), incentivos } \\
\text { fiscais para investimento em P\&D. } \\
\text { - Programa de Incentivo à Inovação Tecnológica } \\
\text { e Adensamento da Cadeia Produtiva de } \\
\text { Veículos Automotores (Inovar Auto). }\end{array}$ \\
\hline & & $\begin{array}{l}\text { Investimento } \\
\text { obrigatório }\end{array}$ & $\begin{array}{l}\text { - Política de Fomento em PD\&l, Agência Nacional do } \\
\text { Petróleo, Gás Natural e Biocombustíveis (ANP). } \\
\text { - Programa de Pesquisa e Desenvolvimento } \\
\text { Tecnológico do Setor de Energia Elétrica, da } \\
\text { Agência Nacional de Energia Elétrica (ANEEL). }\end{array}$ \\
\hline & \multicolumn{2}{|c|}{$\begin{array}{l}\text { Apoio financeiro direto, } \\
\text { implementados, principalmente, } \\
\text { pelo MCTIC, BNDES e FINEP }\end{array}$} & $\begin{array}{l}\text { - Formação de recursos humanos (bolsas) para } \\
\text { formação de mestres e doutores e demais bolsas. } \\
\text { - Construção de infraestruturas físicas, tais } \\
\text { como laboratórios e universidades. } \\
\text { - Recursos reembolsáveis. } \\
\text { - Recursos não reembolsáveis para instituições } \\
\text { científicas e tecnológicas (ICTs) nacionais, } \\
\text { como por exemplo, o Programa Institutos } \\
\text { Nacionais de Ciência e Tecnologia (INCTs). } \\
\text { - Subvenção econômica. } \\
\text { - Capital de risco (investimento anjo, seed } \\
\text { money, venture capital, private equity, } \\
\text { corporate venture, renda variável). }\end{array}$ \\
\hline Orientação à demanda & \multicolumn{2}{|c|}{ Uso do poder de compra do Estado } & $\begin{array}{l}\text { - Lei no } 12.349,2010 \text { : inclui margens adicionais de } \\
\text { preferência para produtos e serviços nacionais. }\end{array}$ \\
\hline
\end{tabular}

O Brasil está entre os cinco países com maior generosidade fiscal em termos de incentivos fiscais à inovação em empresas (por exemplo, deduções, crédito tributário, depreciação acelerada). ${ }^{18}$ No entanto, como comentamos anteriormente, o resultado em termos de inovação e produtividade tem sido pouco significativos. Como constata Carlos Américo Pacheco: "o conjunto do sistema de incentivos brasileiro tem sido, até o presente, pouco eficaz em alterar o quadro de inovação brasileira". ${ }^{19}$

Adicionalmente, é importante ressaltar que programas e ações carecem de avaliações mais sistemáticas sobre seu desempenho e impactos. Alguns programas e ações são descontinuados sem ao menos terem sido submetidos a um processo de avaliação dos benefícios gerados.

\footnotetext{
${ }^{18}$ Para estudo detalhado sobre este tema ver Araujo (2012).

${ }^{19}$ Ver Pacheco (2011, p. 272).
} 


\section{Inovação tecnológica: a necessidade de uma base organizacional}

Propaga-se a ideia segundo a qual para se realizar inovação tecnológica é necessário um estoque de profissionais criativos e qualificados e instalações físicas avançadas (máquinas, equipamentos, laboratórios e prédios inteligentes). Trata-se, porém, de uma noção limitada.

Obviamente que capital humano criativo e qualificado é uma condição necessária para a implementação de inovações. Porém, não é suficiente. Inovação não é meramente criatividade ou ideias brilhantes. Ela envolve um processo de transformação de uma ideia em aplicação prática e comercial, na forma de um produto ou serviço, que adicione valor, atenda a uma demanda (existente ou potencial), assim como a requisitos de viabilidade técnica, econômica e comercial. Para que este processo de transformação se realize são necessárias uma base organizacional e de boa gestão.

Em nível de empresas, onde a inovação tecnológica primordialmente ocorre, esta base organizacional e gerencial envolve um conjunto de rotinas organizacionais, procedimentos e estruturas dedicadas à inovação, tais como unidades de design e desenvolvimento de produto ou processo, engenharia, $P \& D$ e sua rede de parceiros. Envolve também as áreas não tecnológicas correlatas tais como marketing, finanças, operações, distribuição, além da gestão da interface com a rede externa de colaboração.

Ou seja, a implementação de inovações depende da combinação de capital humano, capital físico (equipamentos, máquinas, banco de dados, laboratórios) e do capital organizacional e gerencial. Este último também integra e coordena os componentes anteriores na consecução de inovações. A relação simbiótica entre esses componentes forma um ativo estratégico e idiossincrático denominado de capacidade tecnológica. É por meio da capacidade tecnológica que empresas implementam suas atividades operacionais ou de produção e as suas atividades inovadoras. Interessam-nos aqui as capacidades tecnológicas para inovação.

Por isso, para que empresas inovem, sejam competitivas e gerem uma contribuição significava ao crescimento do país, é necessário que acumulem capacidades tecnológicas inovadoras ao longo de uma 'escada de desenvolvimento tecnológico.' A Figura 9 ilustra este processo de acumulação de capacidades tecnológicas. Este processo não implica linearidade, muito menos automaticidade.

Reiteramos, portanto, que é por meio da acumulação de capacidades para inovação, em nível de empresas e seus parceiros, que países conseguem aumentar o seu desempenho inovador, desempenho exportador e impactar positivamente o crescimento da produtividade e valor agregado. 
Figura 9. Ilustração da 'escada de desenvolvimento tecnológico' em economias emergentes

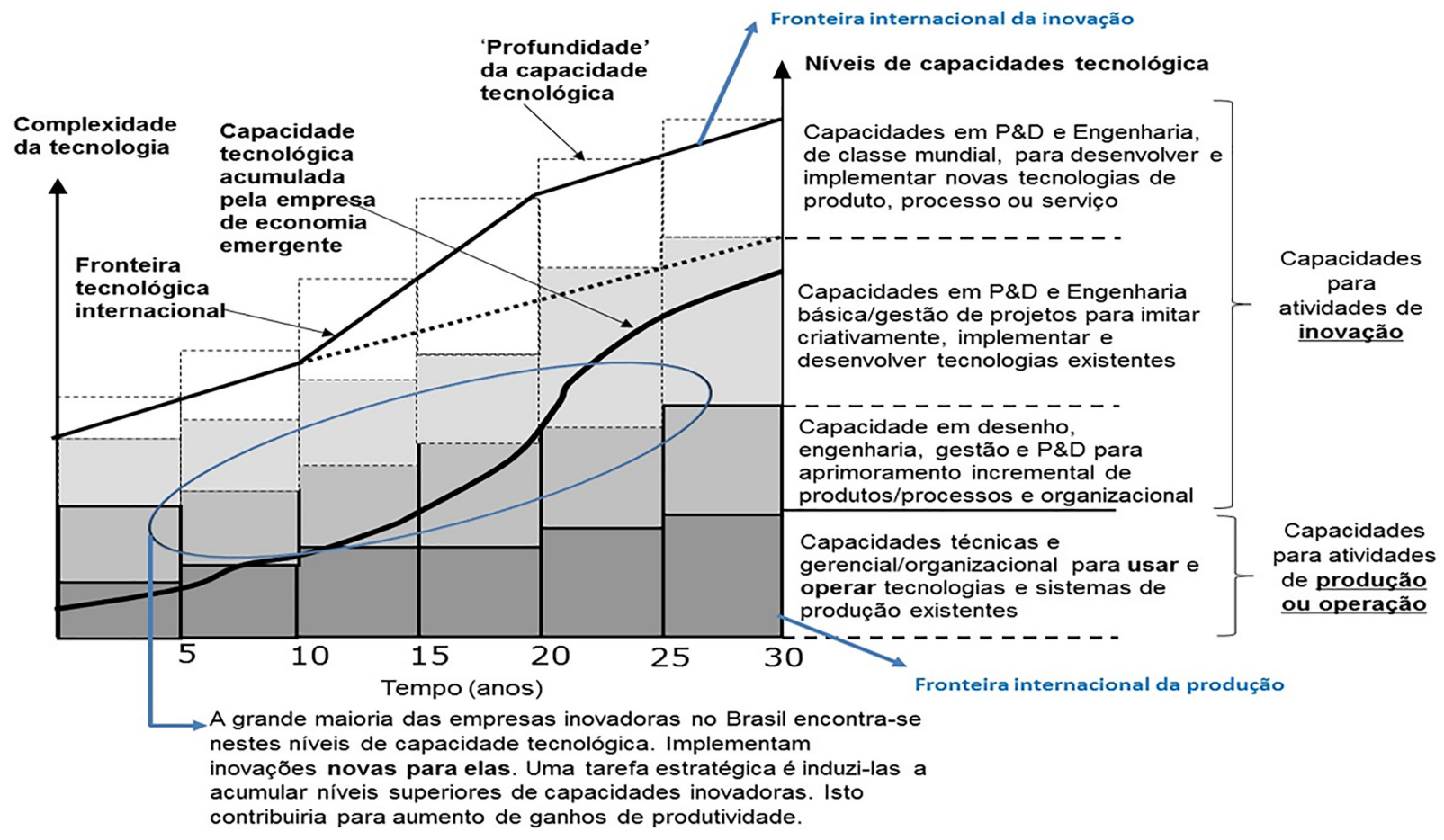

Fonte: Ver Figueiredo (2001, 2015); Bell \& Figueiredo (2012).

No Brasil, costuma-se mirar somente o último degrau da 'escada' da Figura 9. De fato, naquele degrau existem algumas poucas empresas no Brasil, que são exceções, tais como Embraer, Natura, Suzano/Fibria/Klabin, Weg, Marcopolo, Petrobras, Vale, entre outras). Porém, a grande maioria das empresas brasileiras, encontra-se na parte inferior e intermediária da escada. A grande maioria das empresas tem capacidade para implementar inovações novas para elas; uma pequeníssima parcela é capaz de realizar atividades novas para o país e uma parcela menor ainda é capaz de realizar inovações novas para o mundo. ${ }^{20}$ Essas empresas deveriam receber especial atenção nos esforços de políticas de inovação.

Evidências mostram que o tempo necessário para se mover de níveis de inferiores de capacidade tecnológica para níveis avançados (último degrau) é em torno de 20 a 25 anos. Trata-se de um processo árduo e altamente seletivo. Muitas empresas estacionam ao longo do percurso ou mesmo regridem. Portanto, seriam necessárias ações coordenadas para valorizar as atividades inovadoras nas empresas, em termos de design e engenharia, assim como assisti-las no processo de desenvolvimento de capacidades tecnológicas mais avançadas. Ou seja, são necessárias políticas de Estado e não apenas de governo.

\footnotetext{
${ }^{20}$ Ver IBGE/Pintec, 2012-2014.
} 


\section{0 que dissemos, 0 que não dissemos e mais ${ }^{21}$}

O tema da inovação tecnológica tende a se tornar central na discussão sobre o futuro do Brasil. Corrigir o processo atual, que apresenta vários resultados significativos, porém com baixo retorno no seu total, é delicado, pois afetará estruturas de poder consolidadas ao redor da distribuição de verbas públicas. $O$ Estado tem de investir, de preferência mais, mas não há desculpa para não se procurar aumentar o retorno social dos investimentos, independentemente deste aumento ocorrer.

No curto prazo, não existe flexibilidade fiscal para que o Estado amplie seus gastos em P\&D. Também, no curto prazo, a tomada de riscos de P\&D pelo setor privado é pequena. Isto, porém, não significa que não se possa agir.

É preciso entrar nos detalhes do processo de investimento em P\&D mais profundamente e verificar como ele pode ser otimizado. Os esquemas de incentivos precisam ser estudados mais detalhadamente. É necessário que a ligação entre o investimento em ciência básica e o desenvolvimento tecnológico seja mais explorada e melhor compreendida.

O reexame daquilo em que se está investindo e como é de capital importância. Não se pode dizer que tudo tenha a mesma importância que não seja possível um melhor ranqueamento das prioridades. Também é importante a construção de um entendimento comum entre os formuladores de políticas públicas sobre os reais papéis dos atores envolvidos no processo de inovação em nível nacional.

Reiterando, reconhecemos que os investimentos em P\&D não têm o propósito exclusivo de gerar inovação tecnológica. Há objetivos importantes, como, por exemplo, a contribuição para uma base científica no país ou aprimoramento da regulação de atividades econômicas. Ao mesmo tempo, é necessário considerar a premência do aumento da taxa de inovação e produtividade na economia brasileira. Neste sentido, é legítima a preocupação com o aumento da eficácia do dispêndio nacional em P\&D no Brasil.

É fundamental a presença dos agentes responsáveis pela realização do casamento entre as ofertas e as demandas de inovação e as demandas potenciais no processo decisório sobre o investimento em inovação tecnológica.

De fato, o desenvolvimento socioeconômico de um país depende, em grande parte, de uma base científica forte, refletida em universidades capazes de formar massa crítica e realizar pesquisas, nas diversas áreas do conhecimento. Como afirma o professor José Goldemberg (2015, p. 53), a busca de excelência nas universidades contribui para "dar à sociedade os conhecimentos científicos, técnicos e artísticos indispensáveis ao seu desenvolvimento."

Ospaíseshojeindustrialmenteeeconomicamenteavançadoscriaram um vastodomíniotecnológico moldado por demandas, necessidades e incentivos econômicos. A construção desse domínio tec-

${ }^{21}$ O texto desta seção se encontra em processo de elaboração. 
nológico esteve, de várias formas, ligada à ciência. Considerando que a pesquisa científicaé uma atividade altamente dispendiosa, espera-se que ela gere retribuições econômicas e bem-estar à sociedade. ${ }^{22}$

Nos contextos nos quais os programas de pesquisa contribuíram de forma eficaz para o desenvolvimento tecnológico e econômico eles não operaram como 'torres de marfim'. Pelo contrário, orientaram-se para as necessidades e problemas prementes na indústria e na sociedade. ${ }^{23}$ Há casos desta natureza também no Brasil. Por isso, valendo-se de experiências exitosas, seria benéfico para o desenvolvimento nacional se maior atenção fosse dedicada ao desenvolvimento tecnológico e à inovação, bem como à maneira como a ciência pudesse contribuir de maneira eficaz nesta direção. Ou seja, o desenvolvimento científico joga um papel altamente relevante no desenvolvimento tecnológico e socioeconômico de um país. Logo, a ciência não pode ser um fim em si mesma.

Adicionalmente, é preciso reiterar que inovação não deve ser associada a eventos episódicos, nem mesmo a um ponto de chegada. Inovação é, de fato, um processo. É árduo. Longe de refletir qualquer tipo de automaticidade, a sua consecução envolve investimentos e esforços deliberados na construção de seu principal insumo: as capacidades tecnológicas.

Mais especificamente, o processo de inovação e seus impactos no aumento de produtividade e agregação de valor à economia é reflexo, em grandessíssima parte, da maneira como empresas (e sua rede de parceiros) e países acumulam capacidades tecnológicas para inovação. Empresas de economias em desenvolvimento, como a do Brasil, tem deficiências de capacidades tecnológicas inovadoras, por razões históricas. Por isso, o processo de acumulação de capacidades tecnológicas para inovação, em nível de empresas e indústrias, deveria estar no centro do debate e de ações das políticas de inovação no Brasil.

Por fim, reiteramos que o aumento da taxa de inovação é uma das principais condições para o Brasil acelerar o seu crescimento econômico e o seu desenvolvimento social. O processo de inovação demanda investimentos e esforços deliberados. Porém a capacidade governamental para novos dispêndios nessa área é cada vez mais limitada. Ao mesmo tempo, o investimento do Brasil em P\&D ao longo dos últimos 15 anos está longe de ser insuficiente.

Há, ainda assim, um clamor generalizado para o Brasil aumentar o seu investimento em P\&D para se aproximar da média dos países da OCDE, de 2,4\% do PIB. Porém, seria mais sensato priorizar, em primeiro lugar, o aumento da eficácia dos dispêndios existentes antes de simplesmente reivindicar seu aumento. Intensificar o padrão existente de dispêndios em P\&D continuaria a gerar resultados insuficientes.

Mas, se o padrão atual de investimento do Brasil em P\&D permanecer como está, muito provavelmente continuaremos estacionados na condição de economia de renda média: altos custos de produção, baixa capacidade para inovação tecnológica e lento crescimento econômico. As consequências sociais dessa condição são conhecidas. Por isso, é necessário avançarmos no debate sobre o aumento da eficácia dos dispêndios em P\&D no Brasil. Afinal, o investimento eficaz em P\&D é um direito social das gerações futuras do Brasil e um dever da geração presente.

\footnotetext{
${ }^{22}$ Ver Rosenberg (1982) e estudos relacionados.

${ }^{23}$ Ver, por exemplo, Mazzoleni \& Nelson (2007).
} 


\section{7 \\ Alguns projetos potenciais de pesquisa sugeridos por este trabalho}

Este trabalho também contribui para pavimentar o caminho para a emergência de projetos de pesquisa aplicada relacionados ao tema da inovação tecnológica e suas implicações para o desenvolvimento econômico no Brasil. O Quadro 3 a seguir apresenta uma lista não exaustiva de alguns temas potenciais.

Quadro 3. Temas potenciais para projetos de pesquisa aplicada relacionados à economia e gestão da inovação tecnológica no Brasil

\begin{tabular}{|c|c|c|c|c|}
\hline $\begin{array}{l}\text { Temas de natureza } \\
\text { microeconômica }\end{array}$ & $\begin{array}{l}\text { Temas de natureza } \\
\text { macroeconômica }\end{array}$ & $\begin{array}{l}\text { Temas ligados à } \\
\text { política de inovação }\end{array}$ & $\begin{array}{c}\text { Temas ligados à } \\
\text { gestão da inovação } \\
\text { em nível de empresas } \\
\text { e do sistema } \\
\text { de inovação }\end{array}$ & $\begin{array}{l}\text { Oportunidades } \\
\text { para inovação }\end{array}$ \\
\hline $\begin{array}{l}\text { - Estudar o efeito da } \\
\text { composição da dívida } \\
\text { interna sobre a dispo- } \\
\text { sição para investir em } \\
\text { P\&D. } \\
\text { • Estudar o efeito da } \\
\text { oligopolização sobre os } \\
\text { investimentos em P\&D, } \\
\text { em nível de empresas. } \\
\text { - Estudar a microecono- } \\
\text { mia das atuais políticas } \\
\text { de subsídios a P\&D. }\end{array}$ & $\begin{array}{l}\text { - Custo das políticas } \\
\text { macr-oeconômicas de } \\
\text { subsídios à inovação. } \\
\text { • Estratégia cambial } \\
\text { acoplada ao ritmo do } \\
\text { aumento da taxa de } \\
\text { inovação e a pene- } \\
\text { tração em mercados } \\
\text { internacionais. } \\
\text { • 'Efeito Europa' sobre } \\
\text { os investimentos em } \\
\text { inovação. } \\
\text { - Crescimento do setor } \\
\text { de serviços, natureza } \\
\text { do seu processo de } \\
\text { inovação e seu impacto } \\
\text { em produtividade. }\end{array}$ & $\begin{array}{l}\text { - Aprofundar a análise do } \\
\text { perfil dos investimen- } \\
\text { tos em P\&D de outros } \\
\text { países para explicar } \\
\text { medidas de sucesso. } \\
\text { - Examinar o investi- } \\
\text { mento atual sob a ótica } \\
\text { do BSC do país e das } \\
\text { empresas. } \\
\text { - Examinar os entraves } \\
\text { das atuais regulações } \\
\text { e as regulamentações } \\
\text { de P\&D. } \\
\text { - Examinar a política } \\
\text { tributária de P\&D. } \\
\text { - Estudar propostas de } \\
\text { revisão das políticas de } \\
\text { incentivo a P\&D. } \\
\text { - Ranqueamento dos ins- } \\
\text { trumentos de política } \\
\text { de inovação de acordo } \\
\text { com a sua eficácia. } \\
\text { - Identificar maneiras de } \\
\text { sistematizar proces- } \\
\text { sos de avaliação de } \\
\text { programas e ações das } \\
\text { políticas governamen- } \\
\text { tais de inovação. }\end{array}$ & $\begin{array}{l}\text { - Estudar os caminhos } \\
\text { pelos quais se dá } \\
\text { o casamento entre } \\
\text { demanda e oferta no } \\
\text { desenho e implemen- } \\
\text { tação de políticas de } \\
\text { inovação. } \\
\text { - Estudar como a gestão } \\
\text { de recursos humanos } \\
\text { afeta o processo de } \\
\text { inovação. } \\
\text { - Examinar processos } \\
\text { para garantir que a } \\
\text { oferta'niche' a deman- } \\
\text { da em projetos de } \\
\text { inovação. } \\
\text { - Estudar as trajetórias } \\
\text { de acumulação de ca- } \\
\text { pacidades tecnológicas } \\
\text { inovadoras em empre- } \\
\text { sas e seus impactos em } \\
\text { produtividade. } \\
\text { - Identificar junto às uni- } \\
\text { versidades e institutos } \\
\text { de pesquisa as barreiras } \\
\text { organizacionais e legais } \\
\text { que inibem a interação } \\
\text { das mesmas com as } \\
\text { empresas. }\end{array}$ & $\begin{array}{l}\text { - Estudar o processo de } \\
\text { spill-overs dos inves- } \\
\text { timentos em P\&D em } \\
\text { grandes empresas. } \\
\text { - Desenvolvimento de } \\
\text { um 'CRM'/'Market place' } \\
\text { da inovação para esti- } \\
\text { mular a interação entre } \\
\text { empresas e universi- } \\
\text { dades e institutos de } \\
\text { pesquisa. } \\
\text { - Identificar oportunida- } \\
\text { des de diversificação } \\
\text { industrial e criação de } \\
\text { setores industriais e } \\
\text { empresas novos para a } \\
\text { economia. } \\
\text { - Examinar o processo } \\
\text { de agregação de valor } \\
\text { à indústria por meio da } \\
\text { atividade de serviços. }\end{array}$ \\
\hline $\begin{array}{c}\downarrow \\
\text { 3 Temas }\end{array}$ & $\begin{array}{c}\downarrow \\
\text { 4Temas }\end{array}$ & $\begin{array}{c}\boldsymbol{\Downarrow} \\
\text { 7 Temas }\end{array}$ & $\begin{array}{c}\boldsymbol{\downarrow} \\
\text { 5 Temas }\end{array}$ & $\begin{array}{c}\boldsymbol{\Downarrow} \\
\text { 4Temas }\end{array}$ \\
\hline \multicolumn{5}{|c|}{$\begin{array}{c}\boldsymbol{\Downarrow} \\
\text { 23 Temas }\end{array}$} \\
\hline
\end{tabular}




\section{Referências}

ARAUJO, B. C. Políticas de apoio à inovação no Brasil: uma análise de sua evolução recente. IPEA Texto para Discussão 1759, ago. 2012.

BELL, M.; PAVITT, K. Technological accumulation and industrial growth: contrasts between developed and developing countries. Industrial and Corporate Change, v. 2, p. 157-210, 1993.

BELL, M.; FIGUEIREDO, P. N. Building innovative capabilities in latecomer emerging market firms: some key issues. In: CANTWELL, J.; AMANN, E. (Ed.). Innovative firms in emerging market countries. Oxford: Oxford University Press, p. 24-109, 2012.

BRITO-CRUZ, C. H. A pesquisa que o país precisa. RAE Executivo, v. 2, n. 1, fev./abr. 2003.

COHEN, W. M.; LEVINTHAL, D. A. Absorptive capacity: A new perspective on learning and innovation. Administrative Science Quarterly, v. 35, p. 128-152, 1990.

CONFEDERAÇÃO NACIONAL DA INDÚSTRIA (CNI). Competitividade Brasil 2017-2018: Comparação com Países Selecionados. Brasília: CNI, 2018.

EDLER, J. Review of policy measures to stimulate private demand for innovation. Concepts and Effects. NESTA Working Paper 13/13, Manchester Institute of Innovation Research, University of Manchester, november 2013. www.nesta.org.uk/wp13-13.

EDLER. J.; FAGERBERG, J. Innovation policy: what, why, and how. Oxford Review of Economic Policy, v. 33, n. 1, p. 2-23, 2017.

EUROPEAN COMMISSION. Supply and demand side innovation policies. Final Report. Brussels, 2015.

FAGERBERG, J.; MOWERY, D. C.; NELSON, R. R. (Ed.). The oxford handbook of innovation. New York: Oxford University Press, 2005.

FEENSTRA, R. C.; INKLAAR, R.; TIMMER, M. P. The next generation of the Penn World Table. The American Economic Review, 2015.

FIGUEIREDO, P. N. Technological learning and competitive performance. Cheltenham: Edward Elgar, 2001.

FIGUEIREDO, P. N. Gestão da Inovação: conceitos, métricas e experiências de empresas no Brasil. 2. ed. Rio de Janeiro: LTC, 2015.

FREEMAN, C. The economics of industrial innovation. Harmondsworth: Penguin Books, 1974.

GOLDEMBERG, J. Em busca da excelência. Revista USP, n. 105, p. 51-64, abr./maio 2015.

KIM, L. Imitation to Innovation. The dynamics of Korea's technological learning. Boston, MA: Harvard Business School Press, 1997.

KLINE, S. J.; ROSENBERG, N. An overview of innovation. In: LANDAU, R.; ROSENBERG, N. (Eds.). The positive sum strategy: harnessing technology for economic growth. Washington: National Academy Press, 1986. p. 275-304.

LEE, K. Schumpeterian analysis of economic catch-up: knowledge, path-creation, and the middle income trap. Cambridge: Cambridge University Press, 2013. 
MANSFIELD, E. Academic research and industrial innovation. Research Policy, v. 20, p. 1-12, 1991. MAZZOLENI, R.; NELSON, R. R. Public research institutions and economic catch-up. Research Policy, v. 36, p. 1512-1528, 2007.

MEYER-KRAMER, F.; SCHMOCH, U. Science-based technologies: university interactions in four fields. Research Policy, v. 27, p. 835-851, 1998.

PACHECO, C. A. O financiamento do gasto em P\&D do setor privado no Brasil e o perfil dos incentivos governamentais em P\&D. Revista USP, n. 89, p. 256-276, 2011.

ROSENBERG, N. Inside the black box: technology and economics. Cambridge: Cambridge University Press, 1982.

SALTER, A. J.; MARTIN, B. The economic benefits of publicly funded basic research: a critical review. Research Policy, p. 509-532, 2001.

TIDD, J.; BESSANT, J. Managing innovation: integrating technological, market and organizational change. 5. ed. New York: Wiley, 2013. 